Motrivivência $\quad$ v. 28, n. 48, p. 347-359, setembro/2016

\title{
O ESTÁGIO CURRICULAR SUPERVISIONADO NA FORMAÇÃO INICIAL PARA A DOCÊNCIA: as significações dos estagiários como atores do processo
}

Camila Rinaldi Bisconsini ${ }^{1}$

Amauri Aparecido Bássoli de Oliveira

\section{RESUMO}

A pesquisa teve por objetivo analisar o papel do estágio curricular supervisionado na formação inicial de professores, na perspectiva discente. A pesquisa é descritiva e de característica qualitativa. Teve como instrumento para coleta de dados um questionário com questões fechadas e abertas. Participaram 130 discentes de seis cursos de licenciatura de uma Instituição de Ensino Superior Pública do Paraná. Os resultados apontaram um processo de alta complexidade quanto à estrutura e ao desenvolvimento do estágio curricular supervisionado. Os discentes esperavam que os componentes curriculares estabelecessem maior proximidade com as exigências do exercício da profissão docente. Não se evidenciou articulação adequada entre os atores envolvidos no processo.

Palavras-chave: Estágio Supervisionado; Formação Docente; Ensino; Saberes

1 Doutoranda em Educação Física. Programa de pós-graduação associado em Educação Física UEM-UEL. Universidade Estadual de Maringá (UEM). Maringá/Paraná, Brasil. E-mail: camibisconsini@gmail.com

2 Doutor em Educação Física. Professor do Departamento de Educação Física da Universidade Estadual de Maringá (UEM). Maringá/Paraná, Brasil. E-mail: aaboliveira@uem.br 


\section{INTRODUÇÃO}

O estágio curricular supervisionado (ECS) se coloca como um espaço da formação em que os discentes retornam à escola, local que já frequentaram no papel de alunos, como estagiários - futuros professores. Esse é o momento para experimentarem as ações planejadas a partir do que foi aprendido na Instituição de Ensino Superior (IES), além de terem a possibilidade de aplicar e transformar proposições do processo formativo. Em um de seus estudos, Borges (2005) afirma que a escolha da carreira está ligada às experiências anteriores na escola e também às referências da socialização na família e nos diferentes grupos sociais. Nesse sentido, o estágio pode ser um momento de repensar práticas e saberes vivenciados na educação básica. Alguns autores (CARVALHO, 2001; ZANK et al., 2011; OLIVEIRA; BUENO, 2013) destacam o reflexo da experiência escolar como aluno no processo de formação e posterior atuação do professor. Todos estes autores, e outros que também tratam da formação inicial de professores, abordam o entendimento da simetria invertida, a qual aponta a relação entre as vivências escolares do aluno e a prática do professor. Para ampliar a compreensão, destaca-se o Parecer CNE/ CP 009/2001, em que o conceito de simetria invertida expõe a prática do professor, ao apontar a trajetória escolar como constitutiva do papel docente que será exercido na futura atuação profissional.

Entende-se que a IES se constitui como o local e o tempo em que os discentes mobilizam saberes capazes de transformar determinadas práticas, e que, aproximar o acadêmico do futuro lócus de intervenção profissional desde o início de sua formação, poderia capacitá-lo para um enfrentamento mais consistente de todas as adversidades que o meio educacional possui. Em estudo realizado por Moletta et al. (2013), destacou-se que os acadêmicos entendem a escola como um espaço para enriquecer sua formação como professores; entretanto, Pimenta e Lima (2004) afirmam que, se a dinâmica do estágio não for compreendida, o estagiário encontrará problemas em superar as dificuldades que surgem nesse percurso.

É necessário investir na relação profícua entre o docente da graduação, o docente da educação básica e o estagiário, pois somente com a integração dos olhares e vivências será possível uma formação que vá ao encontro do que se exige de um futuro profissional qualificado e mais integrado com as necessidades da educação básica. No entanto, Borges (2005, p. 175) também destaca que "[...] a formação não é um fim em si, e que ela não pode, sozinha, preparar inteiramente os futuros docentes". Ou seja, a formação inicial é apenas parte da constituição do perfil profissional, mas é um período que deve ser discutido no intuito de qualificar esse processo e potencializar determinadas ações, como o ECS.

Por entender que o estágio curricular supervisionado é um momento definido pela legislação que trata dos cursos de Licenciatura (LDB 9.394/1996, Resolução CNE/CP 009/2001, Parecer CNE/CP 28/2001, Resolução CNE/CES 2/2015), e é imprescindível para a aprendizagem dos saberes envolvidos na rotina profissional do professor, acredita-se que é importante levantar a realidade desse processo na perspectiva discente, já que este é o grupo que faz o caminho entre a IES e a escola, tentando vincular e organizar saberes destes dois espaços. 
Considerando os apontamentos, abre-se um pressuposto para a seguinte indagação: "O que os estagiários pensam sobre o papel do estágio curricular supervisionado em sua formação?" Dessa forma, a pesquisa objetivou analisar o papel do estágio curricular supervisionado na formação inicial de professores, na perspectiva discente.

\section{PROCEDIMENTOS METODOLÓGICOS}

A pesquisa tem característica qualitativa. De acordo com Triviños (2011), neste tipo de pesquisa a interpretação dos achados surge como a totalidade de uma especulação que tem como base a percepção de um fenômeno em seu contexto, sendo essa uma forma consistente de alcançar e entender os resultados do estudo. Os dados foram tratados a partir da análise estatística simples.

Participaram estagiários dos cursos de Ciências Biológicas $(n=23$, sendo 19 mulheres e 4 homens, com média de idade de 23 anos), Educação Física ( $\mathrm{n}=22$, sendo 13 mulheres e 9 homens, com média de idade de 23 anos), Geografia ( $n=19$, sendo 9 mulheres e 10 homens, com média de idade de 24 anos), Letras, na habilitação de Português e Literaturas de Língua Portuguesa ( $n=22$, sendo 20 mulheres e 2 homens, com média de idade de 25 anos), História ( $\mathrm{n}=22$, sendo 11 mulheres e 10 homens, com média de idade de 24 anos) e Pedagogia ( $n=22$, sendo 22 mulheres, com média de idade de 25 anos). Estes cursos de licenciatura foram selecionados considerando que o ponto em comum entre todos eles era o nível da educação básica em que os discentes deveriam cumprir o ECS, sendo que, nos cursos citados as vivências do estágio são desenvolvidas nos ensinos fundamental e médio.

Desse modo, participaram discentes (estagiários) do último ano de licenciatura de uma IES pública do norte do Paraná que, no momento de coleta de dados (2012), cumpriam o estágio curricular supervisionado, totalizando 130 discentes. Esse número foi alcançado considerando o total de estudantes que estavam na sala de aula no momento da coleta, a qual foi agendada junto ao coordenador de cada curso. Foram convidados para integrar o estudo os discentes do último ano de cada licenciatura, pois estes já estariam finalizando o ECS e teriam subsídios, a partir de sua experiência nesse momento da formação inicial, para levantar informações sobre o encaminhamento desse processo.

O instrumento utilizado para a coleta de dados foi um questionário com questões fechadas e abertas, e sua elaboração levou em consideração as orientações de Gil (2002). O instrumento continha informações sobre a pesquisa, as razões que motivaram seu desenvolvimento e a importância das respostas para a sua consecução, bem como a instituição a que estava vinculada. Diante dessa delimitação do formato e conteúdo do questionário, foi possível construí-lo de maneira ética e imparcial. A aplicação do questionário foi realizada pelos pesquisadores e autorizada pelos coordenadores dos cursos de licenciatura.

O Termo de Consentimento Livre e Esclarecido - TCLE foi assinado por todos os acadêmicos, para garantia de seu desenvolvimento. A pesquisa teve a aprovação do Comitê Permanente de Ética em Pesquisa Envolvendo Seres Humanos (COPEP) da IES participante, sob o Parecer n. ${ }^{\circ} 16876$. 


\section{RESULTADOS E DISCUSSÃO}

Considerando o interesse dos pesquisadores e os elementos integrantes dos debates que envolvem o estágio curricular supervisionado em cursos de licenciatura, em destaque os autores citados neste estudo e a legislação pertinente já mencionada anteriormente, os resultados e a discussão serão apresentados a partir de oito eixos: a) o envolvimento com o ensino, a pesquisa e a extensão; b) o envolvimento com o estágio não obrigatório; c) o apoio no processo de estágio curricular supervisionado - o planejamento; d) o apoio no processo de estágio curricular supervisionado - o acompanhamento in loco; e) a contribuição do estágio curricular supervisionado para a futura atuação profissional; f) a preparação dos discentes para atuar na escola como estagiários; g) as contribuições do curso para a atuação dos estagiários na escola; e h) a satisfação dos discentes em relação à própria atuação como estagiários. Acredita-se que essas questões são imprescindíveis para perceber a estrutura organizacional e o desenvolvimento do ECS em diferentes cursos de Licenciatura (Ciências Biológicas, Educação Física, Geografia, Letras - Português e Literaturas de Língua Portuguesa, História e Pedagogia), especificamente na perspectiva discente.

\section{O envolvimento com o ensino, a pesquisa e a extensão}

Vale destacar que a universidade busca trabalhar a partir da tríade ensino, pesquisa e extensão, de modo que a formação inicial proporcione ao acadêmico vivências que permeiem estas três vertentes. De acordo com Assis e Bonifácio (2011), é preciso sustentar o compromisso de efetivamente existirem universidades capazes de formar bons professores, críticos, reflexivos e que possam intervir junto à realidade em que se encontram, e um dos caminhos é estimular a participação em projetos de extensão e de iniciação científica.

Pelo fato de ser uma Instituição Pública e de grande porte, o processo de incentivo à participação em projetos de ensino, pesquisa e extensão se coloca como muito forte e em várias frentes. Esse fato é comprovado pelo percentual de discentes participantes nessas atividades, com destaque para a extensão no curso de Educação Física, com participação de 59\% dos discentes. Vale destacar que alguns cursos têm suas particularidades em relação à tríade, como a Educação Física, que tem característica extensionista mais forte. As demais áreas tiveram maior participação na iniciação científica, tendo a seguinte distribuição: Geografia - 47\%, História - 54,5\%, Ciências Biológicas - 78\% de discentes envolvidos. Já no curso de Pedagogia as maiores frequências se dividem entre aqueles que participaram de projetos de ensino e/ ou extensão $(45 \%)$ e aqueles que apontaram não ter participado de nenhuma atividade além das disciplinas da graduação (45\%).

Poucos afirmaram não realizar outras atividades além das disciplinas exigidas pelo projeto pedagógico do curso. Acredita-se que esse compromisso pode refletir nas ações do estágio curricular supervisionado, o que, em nível universitário, depende muito do interesse e da dedicação do discente (BIANCHI; ALVARENGA; BIANCHI, 1998). No espaço do questionário destinado às observações, um dos discentes declarou: "Falta também comprometimento dos gra- 
duandos em procurar se colocar na posição de profissional para fazer melhor uso de sua graduação".

Ghedin, Almeida e Leite (2008), afirmam que a formação deve propiciar um trabalho que aproxime teoria e prática no decorrer do processo, de modo a minimizar a dicotomia na atuação profissional. $\mathrm{Na}$ Resolução CNE/CES 2/2015, que define as Diretrizes Curriculares Nacionais para a formação inicial em nível superior, destaca-se que devem ser destinadas 200 horas de atividades teórico-práticas de aprofundamento em áreas específicas de interesse dos estudantes, pelo menos 2.200 horas dedicadas às atividades formativas, 400 horas de ECS e 400 horas de prática como componente curricular (PCC). Outro destaque para esta Resolução recente, diz respeito à mudança no período de realização do ECS, já que a partir deste documento não se indica a necessidade do estágio ocorrer apenas a partir do início da segunda metade do processo formativo, diferente da Resolução CNE/CP 2/2002. Entendemos então, que há diversas possibilidades na formação inicial para estabelecer uma ponte entre a escola e a universidade, de modo que os estagiários possam aprender com todos os agentes do ambiente escolar, além de favorecer sobremaneira as trocas de saberes entre o ensino superior e a educação básica.

\section{O envolvimento com o estágio não obri- gatório}

No tocante à participação dos discentes em estágios não obrigatórios, percebeu-se que mais da metade dos estudantes de Educação Física $(77 \%)$, Pedagogia (59\%), Ciências Biológicas (78\%), e Letras
(77\%) participaram de estágios não obrigatórios durante sua formação inicial; já nos cursos de Geografia $(63 \%)$ e História $(73 \%)$, a maior parte dos discentes afirmou não ter participado de estágios não obrigatórios durante o curso. Geografia e História têm perfil distinto, já que seus alunos não costumam se envolver com outros estágios, além do obrigatório, lembrando que estes cursos possuem grande parte dos acadêmicos do último ano envolvidos com a iniciação científica, o que pode ser um motivo para os mesmos não buscarem atividades remuneradas por meio de estágios não obrigatórios.

Os resultados indicam que uma alta porcentagem de discentes realiza estágios além do exigido no currículo do curso, o que pode ocorrer pelo fato destes discentes buscarem uma renda mensal para seu sustento, o que o estágio obrigatório não proporciona, no caso das licenciaturas da IES participante. Sobre o assunto, Ramos (2002) aponta, nos resultados de seu estudo, que a remuneração acaba sendo uma justificativa para a realização de estágios não obrigatórios. Em estudo feito por Diniz-Pereira (2011), os resultados apontam que a origem sociocultural da maioria dos aprovados nos cursos de licenciatura é bem menos privilegiada que a dos alunos que optam por cursos mais concorridos. Portanto, há acadêmicos que se vinculam a ações que possam subsidiá-los financeiramente durante o curso.

\section{O apoio no processo de estágio curricular supervisionado - o planejamento}

Os discentes estagiários também foram questionados sobre sua visão acerca das pessoas que mais contribuíram para 
a elaboração do planejamento das aulas no ECS (regências). Libâneo (1990, p. 27) afirma que "A formação profissional é um processo pedagógico, intencional e organizado, de preparação teórico-científica e técnica do professor para dirigir competentemente o processo de ensino". Entende-se que os envolvidos com os cursos de licenciatura devem concentrar esforços coletivos no sentido de haver coerência curricular e compromisso com o formando, para que a elaboração e o desenvolvimento dos conteúdos ocorram em prol do desenvolvimento da própria área.

Para os discentes do curso de Educação Física, a pessoa que mais ajudou a planejar as aulas foi o professor orientador ${ }^{3}$ $(32 \%)$, porém, foi ainda maior o número de estagiários do mesmo curso que afirmou não ter apoio no planejamento de suas aulas $(36 \%)$. Vale ressaltar que essa frequência pode ter sido alta pela falta de iniciativa dos próprios estagiários de buscarem ajuda dos seus orientadores ou do supervisor para a elaboração do planejamento. Mas para isso, o estagiário precisa ter claros os fundamentos, a natureza e os objetivos do estágio, as possibilidades e limitações curriculares, para que ele entenda a dinâmica do processo e se considere parte do mesmo (PIMENTA; LIMA, 2004).

Em relação ao curso de Geografia, as maiores frequências aparecem entre os que afirmaram ser o professor orientador $(47 \%)$ aquele que mais auxilia na elaboração do planejamento, bem como o professor da disciplina de estágio na IES $(47 \%)$. Nos cursos de História (50\%), Pedagogia (82\%),
Ciências Biológicas (87\%) e Letras (82\%) a ajuda parte, principalmente, dos professores do componente curricular "Estágio Curricular Supervisionado". Cabe destacar que nestes cursos, especificamente, o papel de professor orientador era cumprido pelo próprio professor da disciplina de ECS, sendo esta a razão para nenhum dos respectivos discentes ter citado o orientador como aquele que contribuiu para a elaboração do planejamento. Já nos cursos Educação Física e Geografia, o papel do professor orientador era cumprido por outros docentes do departamento, além do professor responsável pelo componente curricular "Estágio Curricular Supervisionado".

Têm-se respostas diferenciadas em relação ao apoio que se oferece aos alunos de licenciatura para pensarem o planejamento que será materializado na escola durante o ECS, o que pode ter ocorrido pelas especificidades de cada curso. O planejamento é uma tarefa complexa que exige o envolvimento entre orientador, supervisor e estagiário, já que este, nesse momento da formação, ainda não possui a expertise necessária para elaborar sozinho esse documento e executá-lo.

\section{O apoio no processo de estágio curricular supervisionado - o acompanhamento in loco}

Acerca da necessidade de visitas do professor orientador ao campo de estágio no momento das regências tem-se, no entendimento dos discentes de todos os cursos, que as visitas são necessárias, porém

3 Para as discussões do presente artigo, o professor orientador é o docente da Instituição de Ensino Superior responsável por acompanhar o estagiário durante as fases de observação, participação e regência. O professor supervisor é aquele que atua na Educação Básica e recebe os estagiários na escola, acompanhando-os. 
somente no curso de Ciências Biológicas essa necessidade foi unânime entre os estudantes. Os resultados demonstram que existe a preocupação dos discentes no que se refere ao acompanhamento do estágio por parte dos orientadores. Ao se referir ao estágio obrigatório, Ayoub e Prado (2012, p. 1207) destacam que "[...] o entrosamento entre os sujeitos envolvidos no processo é fundamental para a concretização de práticas formativas significativas".

Os estudantes de licenciatura expõem a importância do envolvimento dos orientadores com as ações do ECS. Tal fato pode indicar que os estagiários se sentem mais seguros com a presença de seus professores nas regências, já que esse acompanhamento pode oportunizar: a avalição dos estagiários; o feedback em relação à sua postura didática; a aproximação entre IES e escola; o levantamento dos desafios expostos em sala de aula para serem discutidos nas salas da graduação; a avaliação da materialidade do planejamento (que em condições ideais teria sido feito por estagiário, supervisor e orientador); entre outros. Assim, entende-se que o acompanhamento do orientador poderia ser contínuo nas ações do ECS.

\section{A contribuição do estágio curricular supervisionado para a futura atuação profissional}

Os acadêmicos também foram questionados a respeito da contribuição do ECS para sua futura atuação profissional, já que a formação para o ensino deveria ser "uma propedêutica ao trabalho de docente" (BORGES, 2005, p. 174).

Em todos os cursos pesquisados, há aqueles certos de que a experiência no estágio obrigatório ajudou muito durante a preparação para sua futura atuação profissional. Um dos discentes chegou a referir em suas observações: "[...] o último semestre dos cursos de graduação em licenciatura deveria ser totalmente voltado ao estágio obrigatório em regência, nos acostumando assim com a realidade esperada para o fim da graduação". Percebe-se que os acadêmicos entendem a importância de se envolver com ações que os aproxime de sua futura realidade enquanto professores, e alguns demonstram aflição pela ausência ou distância dos orientadores durante o ECS, o que poderia ser minimizado pela maior aproximação entre estes e os discentes, desde o início da graduação.

Em estudo feito por Brandl Neto et al. (2012), os autores realizaram um apanhado de sugestões de estagiários relacionadas às suas práticas nas escolas, e as principais colocações incluíam o aumento da carga horária do estágio, o desenvolvimento das regências em diferentes turmas da escola e a presença do orientador ao menos em uma das regências de cada discente.

Em estudo realizado por Krug (2011), o autor trouxe algumas dificuldades encontradas durante o estágio apontadas pelos discentes, como a indisciplina dos alunos, a falta de espaço físico para as aulas, a falta de domínio da turma, a carência de material para as aulas, o desinteresse dos alunos pelas atividades propostas, a dificuldade em planejar as aulas, e outras. Todavia, vale ressaltar um apontamento feito por Vieira, Santos e Ferreira Neto (2012, p. 135):

[...] o tornar-se professor forma-se ao longo da vida, nos modos com que o futuro educador experimenta o mundo, praticando diferentes cotidianos 
sociais, em um constante aprendizado com os outros homens com quem o mundo é compartilhado.

A formação inicial de professores se constrói a partir dos saberes mobilizados durante a graduação e das experiências de cada acadêmico, que incluem as relações sociais estabelecidas dentro e fora da escola e que fazem parte do processo de formar-se professor. De acordo com Gal-Petitfaux (2005, p. 134), “O ambiente desempenha um papel importante na constituição dos saberes da experiência: planejado pelo docente, ele estrutura, por seu lado, as intervenções". O aluno se integra ao curso de graduação levando consigo as vivências da formação básica, e a partir delas, constrói e reconstrói concepções e conceitos a partir do que aprende em seu curso de formação, levando esse conhecimento para sua prática docente, já como estagiário.

\section{A preparação dos discentes para atuar na escola como estagiários}

Quanto à visão sobre sua preparação para desenvolver as ações necessárias durante o ECS, os discentes de Educação Física (50\%), Geografia (42\%), Pedagogia (45\%), Ciências Biológicas (52\%) e Letras (54\%), consideraram-se parcialmente preparados para atuar nas escolas, no papel de estagiários. Isso acontece, talvez, porque os currículos são constituídos por um aglomerado de disciplinas isoladas e desconexas da realidade profissional (PIMENTA; LIMA, 2004). Já no tocante ao curso de História, a maior porcentagem dos discentes (45\%) se considerou preparada para desenvolver as aulas.

Alerta-se para o fato de a formação docente ser constituída a partir de todo um conjunto de vivências anteriores e simultâneas à fase de graduação, além das aprendizagens que continuam a ser fundadas posteriormente a esse período. Carvalho (2001) aponta que a familiaridade com o futuro campo de trabalho pode levar o estagiário a desenvolver conflitos, pois suas crenças anteriores, advindas da aprendizagem pela observação na condição de aluno, atuam como elemento de resistência para que se possam acomodar novas crenças. A autora alerta para um aspecto conflituoso dessa bagagem deslocada da vivência enquanto aluno na educação básica, considerando que essa experiência pode atuar como um fator de resistência à transformação de determinadas posições, ao invés de servir como um aspecto propulsor de atitudes novas diante da realidade encontrada.

\section{As contribuições do curso para a atuação dos estagiários na escola}

Em relação à visão dos discentes acerca da preparação do curso para a realização do estágio curricular supervisionado, a maior porcentagem dos discentes de Educação Física (41\%), Geografia (42\%), Pedagogia (55\%) e Letras (68\%) afirmou que seu curso preparou pouco para a atuação no ECS, como destacou um dos discentes em suas observações: "[...] quando vamos para as escolas, temos um vasto conteúdo teórico, porém não sabemos aplicá-lo". Corroborando com essa afirmação, Borges (2005) afirma que esse sentimento aparece logo que os estudantes entram em sala de aula e descobrem que não podem transpor na prática as teorias adquiridas na universidade. A mesma autora, ao relatar uma de suas pesquisas, aponta que os professores responsáveis pelo acolhimento e pela inserção dos estagiários nas suas salas de aula 
não se reconheciam dentro da formação inicial, a consideravam distante da realidade escolar, e avaliavam ter aprendido a ensinar em suas próprias práticas profissionais.

No curso de História as maiores porcentagens se dividem entre aqueles certos de que o curso preparou muito pouco $(45 \%)$ e pouco $(45 \%)$ para suas ações no estágio. Em relação ao curso de Ciências Biológicas, há os que consideraram que seu curso de graduação preparou pouco $(39 \%)$ e os que afirmaram que o curso preparou muito (39\%) para sua atuação no ECS. Essa discrepância em relação a este último curso pode ter se dado pelas particularidades de cada discente em relação ao seu envolvimento com projetos de pesquisa e extensão durante o curso, o que reflete sobremaneira na visão destes estudantes sobre as contribuições da formação inicial para sua experiência no estágio.

Também é preciso destacar que os discentes precisam se sentir responsáveis por sua formação, buscando subsídios de aprimoramento para enriquecer sua aprendizagem sobre a atuação profissional. Em estudo feito por Garcez et al. (2012), os discentes que participaram da pesquisa admitiram que o sentimento de responsabilidade é essencial durante a formação docente, principalmente no período de estágio, pois essa é uma característica indispensável no momento em que eles se comprometem com o ensino, com os alunos e com os professores supervisores.

\section{A satisfação dos discentes em relação à própria atuação como estagiários}

Sobre a satisfação dos discentes em relação às suas próprias ações durante o ECS, os discentes de Geografia (42\%) e Ciências Biológicas (48\%) afirmaram estar satisfeitos com as vivências nas escolas como estagiários. Por sua vez, os discentes de História (50\%), Pedagogia (59\%) e Letras $(50 \%)$ apontaram que se sentiam parcialmente satisfeitos durante o estágio. Já os discentes de Educação Física disseram estar insatisfeitos (45\%) com o ECS. Percebe-se que não há consenso entre estes discentes de licenciatura sobre a satisfação em relação à sua própria atuação como estagiários nas escolas, e isso pode ter ocorrido pelo envolvimento de cada discente nas ações de ensino, pesquisa e extensão.

Ressalta-se o fato de que em Educação Física e História apenas $23 \%$ dos discentes se sentiram satisfeitos com a realização dos estágios, o que pode revelar que eles não foram bem-sucedidos nessas atividades. Em estudo feito por Valsecchi e Nogueira (2002), os autores concluíram que a satisfação dos discentes em realizar os estágios varia, entre outros fatores, de acordo com a comunicação entre o supervisor e o discente. Pimenta e Lima (2004) ainda asseguram que a função do orientador é refletir com seus alunos sobre as vivências que já trazem, e vislumbrar um novo conhecimento que ressignifique suas práticas, ponderando as condições objetivas, a história e as relações de trabalho.

É preciso ficar claro que, independente do curso de graduação, os componentes curriculares devem garantir, de forma teórica e prática, o acesso aos conhecimentos pertinentes, cada um com sua especificidade (MORANDINO, 2003). Nesse aspecto, um dos discentes relatou durante suas observações: "[...] há muitas disciplinas relacionadas ao ensino que são interessantes, mas que trabalham com uma situação 
ideal, muito diferente da que o professor em formação encontra no estágio". Ghedin, Almeida e Leite (2008, p.73) destacam que "o estagiário precisa ser orientado a superar as posições de indiferença e de conformismo diante de situações-problemas com as quais se depara". No entanto, entende-se a dificuldade de abordar e conectar saberes nas diversas disciplinas que compõem o currículo de cursos de licenciatura, pois não são conhecimentos estáticos, mas mutáveis e passíveis de incorporação de novos conceitos e discussões advindas da realidade escolar.

De forma geral, os discentes esperavam que os componentes curriculares estabelecessem maior proximidade com as exigências do exercício da profissão docente, como o domínio de classe, a adaptação aos espaços da escola e, principalmente, o domínio dos conteúdos do livro didático ou aqueles solicitados pelos professores supervisores das escolas. Os estagiários precisam se sentir amparados por seu curso de graduação para que se minimize a sensação de insegurança ao adentrarem em seu campo de atuação, já como professores.

\section{CONSIDERAÇÕES FINAIS}

A fim de contribuir com a formação inicial destinada à docência, utilizou-se o estágio curricular supervisionado como objeto de investigação, já que este é um componente curricular obrigatório nos cursos de licenciatura e uma fase da graduação que pode propiciar rica experiência aos discentes em relação ao âmbito escolar, desde que o processo ocorra de forma organizada e os sujeitos envolvidos se articulem a favor das ações.

A realidade do ECS em cursos de licenciatura está posta como uma rede de relações necessárias à formação inicial de docentes, e como tal, necessita receber a devida importância daqueles envolvidos com a formação de professores, seja como aluno ou como professor. As ações da formação inicial docente precisam estar integradas e se movimentando em prol de um objetivo comum, formar docentes autônomos que reflitam constantemente sobre sua prática, transformando antigas ações em uma realidade de efetiva aprendizagem para os alunos.

Analisamos o estágio curricular supervisionado em diferentes cursos de licenciatura para compreendermos de forma ampliada a perspectiva discente sobre esse momento da formação inicial. Os dados obtidos, lamentavelmente, apontam a fragilidade geral do processo vivenciado, que vai desde a estrutura curricular até o suporte durante as etapas que compreendem o ECS. Dessa forma, aponta-se que há muito a ser feito em prol de uma formação qualificada e que atenda aos anseios dos seus integrantes. Os cursos precisam manter um processo de autoavaliação e buscar superar os quadros de insatisfação e fragilidades. $\mathrm{O}$ ECS é o coroamento de toda a formação da licenciatura, serve como um termômetro do vivenciado e não pode ser tratado apenas como uma ação burocrática. Sua riqueza e importância devem ser consideradas no repensar contínuo dos cursos de formação inicial de professores.

\section{REFERÊNCIAS}

ASSIS, R.M. de; BONIFÁCIO, N.A. A formação docente na universidade: ensino, pesquisa e extensão. Educação e Fronteiras, v.1, n.3, p.36-50, 2011. 
AYOUB, E.; PRADO, G. do V.J. Estágios curriculares na formação de professores de educação física: abordagens interdisciplinares. In: II Congresso Internacional de Formação Profissional em Educação Física e VI Semana de Estudos e Pesquisas em Formação Profissional no Campo da Educação Física, 2012, Florianópolis, Anais... Florianópolis, 2012. p.1197-1211. 1 CD-ROM.

BIANCHI, A.C. de M.; ALVARENGA, M.; BIANCHI, R. Manual de orientação: estágio supervisionado. São Paulo: Pioneira, 1998.

BORGES, C. A formação dos docentes de Educação Física e seus saberes profissionais. IN: BORGES, C.; DESBIENS, J-F. (Org.). Saber, formar e intervir para uma educação física em mudança. Tradução: Amin Simaika. Campinas, SP: Autores Associados, 2005. p.157-190.

BRANDL NETO, I.; et al. A importância do estágio supervisionado na formação inicial do professor de educação física. In: II Congresso Internacional de Formação Profissional em Educação Física e VI Semana de Estudos e Pesquisas em Formação Profissional no Campo da Educação Física, 2012, Florianópolis, Anais... Florianópolis, 2012. p.1007-1021. 1 CD-ROM.

BRASIL. Presidência da República. Lei $\mathbf{n}^{\circ}$ 9.394, de 20 de dezembro de 1996 . Estabelece as Diretrizes e Bases da Educação Nacional. Diário Oficial [da República Federativa do Brasil], Brasília, DF, v.134, n.248, 23 dez. 1996. Seção 1, p.2783427841, 1996.

. Ministério da Educação. Conselho Nacional de Educação. Parecer CNE/ CP 009/2001. Diretrizes Curriculares
Nacionais para a Formação de Professores da Educação Básica, em nível superior, curso de Licenciatura, de graduação plena. Brasília, DF, 2001. . Ministério da Educação. Conselho Nacional de Educação. Parecer CNE/CP 28/2001. Dá nova redação ao Parecer CNE/CP 21/2001, que estabelece a duração e a carga horária dos cursos de Formação de Professores da Educação Básica, em nível superior, curso de licenciatura, de graduação plena. Brasília, DF, 2001.

Ministério da Educação. Conselho Nacional de Educação. Resolução CNE/ CP $\mathbf{n}^{\mathbf{0}} \mathbf{0 2}$ de 19 de fevereiro de 2002. Brasília, DF, 2002.

. Resolução 2, de 1 de julho de 2015. Ministério da Educação. Conselho Nacional de Educação. Brasília, 2015.

CARVALHO, A.M.P.D. de. As influências das mudanças da legislação na formação dos professores: as 300 horas de estágio supervisionado. Ciência e Educação, v.7, n.1, p.113-122, 2001. Disponível em: < http://www.scielo.br/pdf/ciedu/ v7n1/08.pdf $>$. Acesso em: 24 ago. 2012.

DINIZ-PEREIRA, J.E. O ovo ou a galinha: a crise da profissão docente e a aparente falta de perspectiva para a educação brasileira. Revista Brasileira de Estudos Pedagógicos, v.92, n.230, p.34-51, 2011. Disponível em: < http://rbep. inep.gov.br/index.php/RBEP/article/ viewFile/1772/1380 >. Acesso em: 14 dez. 2014.

GAL-PETITFAUX, N. Saberes e ação situados: uma análise das práticas de ensino de educação física. IN: BORGES, C.; DESBIENS, J-F. (Org.). Saber, formar e intervir para uma educação física em 
mudança. Tradução: Amin Simaika. Campinas, SP: Autores Associados, 2005. p.113-137.

GARCEZ, E.S. da C. et al. O Estágio Supervisionado em química: possibilidades de vivência e responsabilidade com o exercício da docência. Alexandria Revista de Educação em Ciência e Tecnologia, v.5, n.3, p.149-163, 2012. Disponível em: < http://alexandria.ppgect.ufsc.br/ files/2012/11/Edna.pdf $>$. Acesso em: 20 set. 2012.

GHEDIN, E.; ALMEIDA, M.I. de.; LEITE, Y.U.F. Formação de professores: caminhos e descaminhos da prática. Brasília: Líber Livro, 2008.

GIL, A.C. Como elaborar projetos de pesquisa. 4. ed. São Paulo: Atlas, 2002. KRUG, H.N. Os problemas/dificuldades na prática pedagógica nos estágios curriculares I-II-III na percepção dos acadêmicos na Licenciatura em educação física do CEFD/UFSM. EFDeportes.com, v.16, n.158, p. s/d, 2011. Disponível em: <http://www. efdeportes.com/efd158/os-problemasna-pratica-pedagogica-em-educacaofisica.htm > . Acesso em: 13 set. 2012.

LIBÂNEO, J.C. Didática. 28. reimpr. São Paulo: Cortez, 1990.

MOLETTA, A.F. et al. Momentos marcantes do estágio curricular supervisionado na formação de professores de educação física. Pensar a Prática, v.16, n.3, p.619955, 2013.

MORANDINO, M. A prática de ensino nas Licenciaturas e a pesquisa em ensino de ciências: questões atuais. Caderno Brasileiro de Ensino de Física, v.20, n.2, p.168-193, ago. 2003. Disponível em: <http://www.fsc.ufsc.br/cbef/ port/20-2/artpdf/20-2.pdf > . Acesso em: 14 set. 2012.

OLIVEIRA, A.S. de.; BUENO, B.O. Formação às avessas: problematizando a simetria invertida na educação continuada de professores. Educação e Pesquisa, v.39, n.4, p.875-890, 2013.

PIMENTA, S.G.; LIMA, M.S.L. Estágio e docência. São Paulo: Cortez, 2004.

RAMOS, G.N.S. Os estágios extracurriculares na preparação profissional em Educação Física. Movimento e Percepção, Espírito Santo, v.1, p.127-141, 2002. Disponível em: < http://www.ufscar.br/ defmh/ spqmh/pdf/creupglau.pdf > . Acesso em: 14 nov. 2012.

SANTOS, B. de S. Porque é tão difícil construir uma teoria crítica? Revista Crítica de Ciências Sociais, v. s/d, n.54, 1999. Disponível em: < https://estudogeral.sib.uc.pt/ bitstream/10316/10808/1/Porque $\% 20$ \% C $3 \%$ A $9 \% 2$ t \% C $3 \%$ A 3 o \% 20 dif $\%$ C $3 \%$ ADcil $\% 20$ construir $\% 20$ uma \% 20teoria \% 20cr\% C3\% ADtica. pdf $>$. Acesso em: 23 set. 2012.

TRIVIÑOS, A.N.S. Introdução à pesquisa em ciências sociais: a pesquisa qualitativa em educação. São Paulo: Atlas, 2011.

VALSECCHI, E.A. de S. da S.; NOGUEIRA, M.S. Comunicação professor-aluno: aspectos relacionados ao estágio supervisionado. Revista Ciência, Cuidado e Saúde, Maringá, PR, v.1, n.1, p.137-143, 2002. Disponível em: <http://periodicos.uem.br/ojs/ index.php/CiencCuidSaude/article/ view/5684/3608 > . Acesso em: 23 jun. 2012.

VIEIRA, A.O.; SANTOS, W. dos; FERREIRA NETO, A. Tempos de escola: narrativas da formação discente ao ofício docente. 
Movimento, Porto Alegre, v.18, n.3, p.119-139, jul./set. 2012. Disponível em: < http://seer.ufrgs.br/Movimento/ article/view/28131/21142>. Acesso em: 11 nov. 2012.
ZANK, V.; et al. O curso de especialização em docência para a educação profissional: inovando para formar, formando para inovar. Competência, v.4, n.1, p.11-26, 2011.

\title{
THE SUPERVISED CURRICULAR INTERNSHIP IN THE INITIAL TRAINING FOR TEACHING: THE MEANINGS OF TRAINEES AS ACTORS IN THE PROCESS
}

\begin{abstract}
The research aimed to analyze the role of supervised curricular internship in initial teacher education, in the trainees perspective. The research is descriptive and qualitative characteristic. Had as a tool for data collection a questionnaire with closed and open questions. 130 trainees participated in six degree courses of an institution of Paraná Public Higher Education. The results indicate a process of high complexity on the structure and development of supervised curricular internship. The trainees hoped that the curriculum components establish closer to the requirements for the exercise of the teaching profession. There was no evidence is sufficient interaction between the actors involved.
\end{abstract}

Keywords: Supervised Curricular Internship; Teacher Training; Education; Knowledge

\section{EL CURSO SUPERVISADA EN FORMACIÓN INICIAL PARA LA ENSEÑANZA : LOS SIGNIFICADOS DE LOS ALUMNOS COMO ACTORES PROCESO}

\section{RESUMEN}

La investigación tuvo como objetivo analizar el papel de las curricular supervisó la formación inicial de los docentes en la perspectiva de los estudiantes. La investigación es una característica descriptiva y cualitativa. Tenía como herramienta de recolección de datos un cuestionario con preguntas cerradas y abiertas. 130 estudiantes participaron en seis cursos de pregrado de una institución de educación superior pública de Paraná. Los resultados muestran un proceso de alta complejidad de la estructura y el desarrollo de curricular supervisada. Los estudiantes esperan que los componentes curriculares establecen más estrecha con los requisitos para el ejercicio de la profesión docente. No hubo evidencia de una adecuada coordinación entre los actores involucrados.

Palabras clave: Formación Supervisada; La Formación del Professorado; Educación; Conocimiento 